\title{
Hierarchical Effect of Psychosocial Factors and Job Satisfaction on Academic Staff Commitment to the University: The Case of University of Cape Coast, Ghana
}

\author{
Joyce Kwakyewaa Dankyi, Isaac Eliot Nyieku \\ College of Distance Education, University of Cape Coast, Cape Coast, Ghana \\ Email: joyce.dankyi@ucc.edu.gh
}

How to cite this paper: Dankyi, J. K., \& Nyieku, I. E. (2021). Hierarchical Effect of Psychosocial Factors and Job Satisfaction on Academic Staff Commitment to the University: The Case of University of Cape Coast, Ghana. Open Journal of Social Sciences, 9, 372-386.

https://doi.org/10.4236/jss.2021.93024

Received: February 17, 2021

Accepted: March 26, 2021

Published: March 29, 2021

Copyright $\odot 2021$ by author(s) and Scientific Research Publishing Inc. This work is licensed under the Creative Commons Attribution International License (CC BY 4.0).

http://creativecommons.org/licenses/by/4.0/

\begin{abstract}
The determinants of staff retention and productivity in higher education institutions are of enduring importance to both researchers and policymakers. The purpose of the study was to investigate the incremental effects of psychosocial factors and job satisfaction on academic staff commitment to the University of Cape Coast (UCC). A quantitative descriptive survey design was used and 268 academics were recruited via stratified random sampling technique. The response rate was $97.4 \%$ with an instrument reliability coefficient of 0.857 . Data were analysed using hierarchical multiple regression analysis. The study found that academics generally perceived psychosocial factors positively, although to varying degrees. The order of importance of the predictors of the commitment of academics was work-family conflict $>$ work environment $>$ promotion. Job satisfaction on its own, contributed $50.6 \%$ to the commitment levels of academics. However, when job satisfaction was combined with psychosocial factors, the level of commitment of academics increased by almost thirty-five percent, suggesting that psychosocial factors and job satisfaction of academics had positive and incremental effect on the commitment of academic staff to the University. Management of the University should put in place measures that will help enhance staff job satisfaction and commitment through guidance and counselling interventions.
\end{abstract}

\section{Keywords}

Academics, Commitment, Job Satisfaction, Psychosocial Factors, University, Ghana 


\section{Introduction}

Globally, staff commitment has become a "burning" issue in vocational/career counseling as evidence mounts on the critical role it plays in determining the total well-being of an employee. It largely affects employees' productivity, absenteeism, turnover rate, and performance (Abou-Hashish, 2017; Staniok, 2019). Consequently, it is important for counsellors and other professionals to help staff understand themselves and their environment so as to make informed decisions leading to their commitment. One of the factors that can be isolated for attention in order to boost staff commitment in universities globally is staff psychosocial factors and their satisfaction. Several studies have devoted copious attention to the independent effects of psychosocial factors and job satisfaction on staff commitment. What is missing from the extant literature is the combined effect of both set of factors, which is the moderating role they play in predicting staff commitment.

The current trend regarding academics job satisfaction and commitment to their universities leaves much to be desired. Milledzi et al. (2018) are of the view that lecturers perceive their psychosocial factors negatively which, to a large extent, affect their job satisfaction level. Noble and McCormic (2015) also posit that institutional and personal factors, to a large extent, have a meaningful influence on teachers job satisfaction and their commitment to the schools. This shows that there is the need to find out what makes staff satisfied and committed to their organization, and the role psychosocial factors play in achieving that.

In examining employees' job satisfaction and commitment, current studies depicts that most researchers considered only organizational factors without due attention to psychological and social factors such as promotion, the nature and scope of the work, work environment, co-worker relationship and work-family conflict (Frempong et al., 2018; Yiğitol \& Balaban, 2018). Also, most of these previous studies on this subject have been situated in organizational or corporate settings, with the academic circles largely missing, particularly universities (Abou-Hashish, 2017; Fuudia, 2017). This study focuses on the University of Cape Coast, one of the oldest public universities in Ghana to assess the joint effect of psychosocial factors and job satisfaction on the commitment of academics. This higher education institution was chosen based on the diversity of academic staff and the longstanding contribution to higher education in the Ghanaian context.

\subsection{Purpose of the Study}

The purpose of the study was to investigate the incremental effects of psychosocial factors and job satisfaction on academic staff commitment to the University of Cape Coast.

\subsection{Research Hypothesis}

In line with the purpose of the study, a hypothesis was formulated to direct the argument: 
H0: Psychosocial factors and job satisfaction have no statistically significant incremental effects on academic staff commitment at University of Cape Coast.

\subsection{Significance of the Study}

Job satisfaction and academics commitment to universities have implications for relations between the academics and the management of the universities. Therefore, the findings of this study would serve as an evidence-based research material to management of the University to modify their human resource management policies and practices that are psychological and social in nature in order to enhance academics job satisfaction and commitment. The findings will also help practitioners and researchers in the area of vocational counselling and higher education to better understand the concept of psychosocial factors, and the extent to which this variable influences academic staff job satisfaction. This will also help career counsellors to identify areas that they need to intensify their guidance and counselling. Also, it will constitute a significant source of literature in the area of staff psychosocial factors and commitment.

\subsection{Delimitation}

Geographically, the study was delimited to UCC, Ghana. However, a complementary survey addressing all public universities in Ghana will give additional depth to the study. Also, the study was delimited to psychosocial factors (the nature and scope of the work, work environment, promotion, co-worker relation, and work-family conflict), job satisfaction and commitment of academics. In relation to respondents, the study was delimited to full-time academics of UCC. Part-time academics were excluded from this study since they are not exposed more to the ways of doing things in the University and as a result will be difficult to examine their views on psychosocial factors and it influence on their job satisfaction and commitment.

\section{Literature Review}

Universities are institutions saddled with the responsibilities of preparing and producing high level workforce for the economy. In these institutions, academics occupy a central place in the teaching and learning processes within the system and for that matter responsible for the training of the human resource for the country's economy. Considering this important role, the commitment of academics should be a thing of concern to the universities and the country as a whole. The quality of services provided by academics to a large extent is dependent on their satisfaction and commitment to the universities (Azeem \& Akhtar, 2014; Frempong, Agbenyo, \& Darko, 2018). Largely, it is the activities of academics that society uses to determine or rate the performance of universities. Therefore, it is important that stakeholders seeking to influence the role of universities in the knowledge society understand what influences university academics job satisfaction and commitment, in order to help them work effectively 
in their everyday circumstances.

Psychosocial factors such as the nature and scope of the work, promotion, work environment, co-worker relationship and work-family conflict can help enhance academics job satisfaction and commitment to the universities. According to Milledzi, Boateng, Amponsah and Opare (2018), psychosocial factors are considered as factors that help in strengthening the mental process and behaviour of people and groups in an organisation or society. However, the same factors, when perceived negatively, can produce negative behaviours which usually lead to non-commitment of academics. Staff commitment on the other hand refers to the relative emotional strength of staff identification with and involvement in a particular organisation (Saani, 2017). Managers are always seeking ways to enhance employee commitment and generate greater competitive advantages. Lack of commitment can hinder ordinary day to day operations, efficiency of task completion and absence of customer satisfaction (Staniok, 2019). Therefore, it is appropriate for researchers to examine psychosocial factors of staff in order to understand their role on academics job satisfaction and commitment.

The reasons for examining academics job satisfaction and commitment may range from practical to humanistic. On the practical aspect, there has been persistent belief among management of universities that a strong relationship exists between staff commitment and work performance (Noble \& McCormic, 2015; Saani, Opare, \& Yarquah, 2014). Therefore, there is considerable interest in understanding staff commitment so that strategies can be devised to boost it through the creation of conducive and appropriate psychosocial interventions. On the humanistic aspect, academics, out of necessity, spend a considerable portion of their lives at the workplace. Much of life would be miserable if the workplace offers no opportunity for satisfaction and commitment. Job satisfaction and staff commitment are functions of a variety of features of the work environment and they are critical in determining a number of important outcomes such as creating conducive environment and better support services at the work place that enable employees to be creative, efficient and innovative (Milledzi et al., 2018). The reasons highlighted show that psychological and social factors of academics are crucial in determining their job satisfaction and commitment to the university.

Verret (2012) investigated factors affecting university Science, Technology, Engineering and Mathematics (STEM) faculty staff job satisfaction in five research universities in the United States of America. Pearson product moment correlation and multiple regression analysis were performed. The results showed that rank, gender, marital status and salary have significant effects on the levels of job satisfaction of STEM faculty staff. The study also showed that a significant relationship existed between work-family conflict and levels of job satisfaction of STEM faculty staff. The findings of this study are consistent with other studies reviewed. For example, Noble and McCormic (2015) in their study found academic rank as a reliable predictor of job satisfaction. Similarly, Ssesanga and Gar- 
rett (2016) in a study of university academics concluded that academic rank has a significant effect on levels of job satisfaction. On the other hand, some empirical studies reviewed showed contradictory findings. For instance, Nestor and Lary (2016) found no significant relationship between gender and levels of job satisfaction. The literature is so far divergent. Some empirical studies reviewed have indicated that males are more satisfied with their jobs while others contend that females are more satisfied with their jobs. Due to the inconsistencies in the literature, further research is needed.

Ismail (2016) also examined the relationship between components of organizational commitment and job satisfaction among employee at Higher Learning Education Institutions in Kelantan. The study was able to make important contribution to extant research in management and organizational behavior. In the beginning of this study, the purpose, research question, and the need for the study were given. Then, literature was discussed about organizational commitment and job satisfaction that focusing on the relationship between them. The study generated a 96.3 percent response rate from 300 respondents. The result showed that affective, continuance and normative commitment that was not found to have significant positive relationship with job satisfaction.

Furthermore, Alsemeri (2016) also examined the causes and effects of job satisfaction among public sector workers in Saudi Arabia. A job satisfaction model was developed based on theories supporting factors in job satisfaction, organizational commitment, and intention to leave and the research questions were tested within the scope of the model. The results indicated that the intrinsic factors with the highest effect on job satisfaction were job security, moral values, achievement, and social service, while the least influential were using judgement, opportunity to be innovative, working autonomously and challenging work. In terms of the extrinsic factors supervisor relationships, competency of supervisor, recognition, and co-workers relationships were important, while organizational policies, promotion, and working conditions were placed lower on the scale.

In terms of the effect of job satisfaction, Alsemeri (2016) found out that there was a high level of commitment and relatively low level of intention to leave, although this was more due to pragmatic concerns of earning a livelihood rather than emotional commitment to the organization. Of the commitment classifications (affective, continuance, normative), continuance was found to be the most important as the respondents felt that they had no other job options. The respondents appreciated their "steady jobs" and 72.5 per cent had no intention to leave the organization; this outcome was influenced by age and classification. Furthermore, employee's satisfaction and performance is important and necessary in an organisation. A satisfied employee would have higher performance and it will increase the productivity. A university is the place where deliver knowledge to students and train them to be the expert in various fields. Understanding academics job satisfaction is necessary in the University to deliver superior performance for university. Therefore, job satisfaction and performance become popular research topic. The main purpose of Yee's (2018) study was to 
investigate the relationship between job satisfaction factors and job performance among academic staff in Malaysian private universities. In this study, job satisfaction discusses in extrinsic and intrinsic factors that are working condition, job security, and remuneration, relationship with colleagues, recognition, and advancement. Job performance looked at the text performance and contextual performance.

Yee's (2018) study was a descriptive research and survey approach that used to observe the correlation among job satisfaction factors and job performance. Job satisfaction factors were the independent variables while job performance was the dependent variable. The study uses five-point Likert scale questionnaire to analyse the independent variables and dependent variables of academic staff. Pearson's correlation coefficient and multiple regression analysis were the data analysis techniques that were used to assess the relationship among independent and dependent variables. The findings revealed that there was a statistically significant positive relationship between academic staff job satisfaction and work performance.

Frempong, Agbenyo and Darko (2018) examined whether job satisfaction has impact on the employees' loyalty and commitment. The study utilized descriptive and exploratory research design. The results showed a significant and positive relationship. Again, individual factor was found to contribute to the satisfaction but did not have a strong impact on job satisfaction in all sectors. The study again portrayed that there was at least a positively significant relation between the human resources practices', job satisfaction and loyalty/commitment in various sectors. Frempong et al. concluded that job satisfaction showed a significant impact on loyalty and commitment in the manufacturing and mining sector and that there was at least significant relationship between the human resource practices, job satisfaction and loyalty/commitment in various sectors. The difference between the current study and the study of Frempong et al. is that psychosocial factors were not investigated in the study of Frempong et al.

Ansong (2018) also examined the issue of job satisfaction among career records personnel in the Civil Service of Ghana. Civil Servants from twenty-seven (27) ministries and PRAAD were selected for the study. The findings indicated that institutional policy, supervision, co-worker relations, promotion, salary, benefits and actual work had a significant and a positive relationship with job satisfaction, but communication had no significant relationship with job satisfaction. Majority of records personnel were less satisfied with some aspects of bureaucracy, salary and benefits in the Civil Service. Ansong's study covered some psychosocial factors which were investigated in the current study such as that satisfaction in the actual work. This was also investigated in the current study.

Baah (2015) investigated employee satisfaction and commitment as antecedents to service quality in hospital service delivery system in Ghana. The study indicated that although employee satisfaction does not directly affect service quality, its effect passes through employee commitment which in turn affects service quality. This implies that, employee commitment fully mediates the relationship between employee satisfaction and service quality. Milledzi, Boateng, 
Amponsah and Opare (2018) also assessed the interaction effects of organisational climate as a key moderating variable on socio-psychological factors that influence levels of job satisfaction among academic staff of universities in Ghana. The result showed that organizational climate was a key moderating variable for job satisfaction among academic staff of universities in Ghana.

\section{Conceptual Framework}

The argument of the study is underpinned by Donald super's career development theory. It was used to support the argument that explains antecedents that make academics of UCC satisfied and committed to the University. Gothard, Mignot, Offer and Ruff (2001) proposed a career theory based on the assumption that career choice and development is essentially a process of developing and implementing a person's self-concept. Super's theory has called for a stronger emphasis on the effects of social context and the reciprocal influence between the person and the environment (Gothard et al., 2001). Life and work satisfaction are continual processes of implementing the evolving self-concept through work and other life roles. Based on the view of Super, one can posits that factors such as physical, mental, personal experiences and environmental have to be in place for individuals to make career choice and develop successfully in it. Thus, psychosocial factors which involve all manner of relationships and how the work environment is structured can influence the extent to which academics can be satisfied and also be committed to the University. The assumption of the study is presented pictorially in Figure 1.

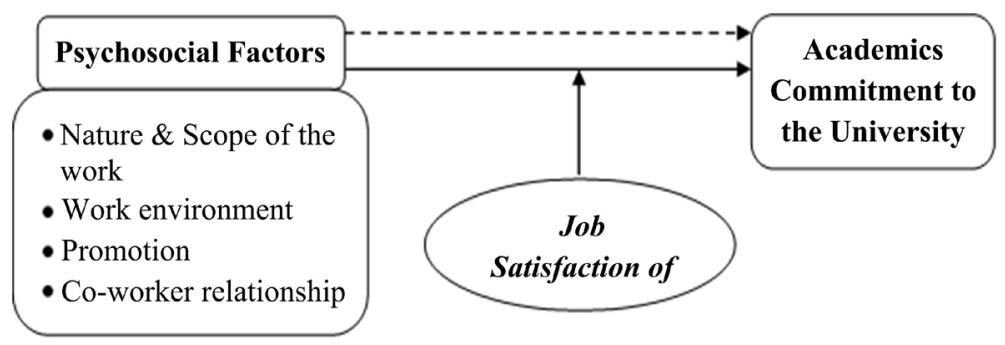

Figure 1. Incremental effects of psychosocial factors and job satisfaction on academic staff commitment to the university.

The assumption behind this study was that psychosocial factors and job satisfaction of academics have predictive incremental effects on academics commitment to the University. It is conceptualized therefore, that when academics perceive their psychosocial factors in positive terms, it will enhance academic staff job satisfaction which in the long run will in turn boost academics commitment to the University.

\section{Research Method}

The study employed the quantitative approach. In relation to design, the descriptive survey design was adopted. This design was adopted because the study entailed a 
survey of academics view on the issues, situations and processes. Descriptive design involves systematic gathering of data about individuals and groups in order to test hypotheses or answer research questions concerning the current status of the subject of the study (Cohen, Manion \& Morrison, 2018). The study population was all permanent academics of UCC. Current records show that there are 811 academics in UCC (Educational Management Information System, EMIS, 2019). A sample of 268 was obtained using Slovin's recommended formula which has been tested and used for most survey and case studies and has the ability to specify the precision of estimation desire for a population (Jain, 2019). The formula is $n=N \div\left[1+N\left(e^{2}\right)\right]$, where $\mathrm{n}$ is the sample size, $\mathrm{N}$, the population size, and e, the level of precision. $n=811 \div\left[1+811(0.05)^{2}\right]=811 \div 3.0275$ $=267.88 \approx 268$. Stratified random sampling that makes use of the computer random number method of simple random sampling technique was used to select the respondents after classifying them into five strata. The sample distribution is presented in Table 1.

Structured questionnaire was the instrument used to collect the data. Responses to the various items in the questionnaire were measured numerically using unilineal scale such that one represents the strongest disagreement while five represents the strongest agreement to the items.

Face and content validity of the instruments were established by experts and professionals in the field of counselling and education. The questionnaire was again subjected to factor analysis to ensure its construct validity. The pre-test data obtained from 49 academics of University of Education, Winneba (UEW) main campus, was analyzed using Cronbach's alpha techniques that yielded a reliability coefficient of 0.857 , which was deemed appropriate (Sarstedt \& Mooi, 2019). The questionnaires were administered personally by the researchers and two research assistants. Out of the 268 questionnaires administered, $261 \mathrm{com}$ pleted questionnaires were retrieved, indicating a $97.4 \%$ response rate. The data were analyzed using hierarchical multiple regression analysis after meeting the normality, homogeneity and multicollinearity conditions.

Table 1. Sample distribution of academic staff of UCC, Ghana.

\begin{tabular}{ccccccc}
\hline \multirow{2}{*}{ Colleges within UCC } & \multicolumn{5}{c}{ Academic Rank of Respondents } & Total \\
\cline { 2 - 6 } & P & AP & SL \& SRF L \& RF & AL & \\
\hline College of Humanities and Legal Studies & 6 & 11 & 30 & 26 & 20 & 93 \\
College of Health and Allied Sciences & 2 & 3 & 13 & 13 & 14 & 45 \\
College of Agriculture and Natural Sciences & 4 & 8 & 24 & 19 & 7 & 62 \\
College of Distance Education & 2 & 3 & 3 & 5 & 6 & 19 \\
College of Education Studies & 4 & 9 & 17 & 9 & 10 & 49 \\
Total & 18 & 34 & 87 & 72 & 57 & 268 \\
\hline
\end{tabular}

Source: Educational Management Information System (EMIS, 2019). Where, P = Professors, AP = Associate Professors, SL\&SRF = Senior Lecturers and Senior Research Fellows, L\&RF = Lecturers, Research Fellows, and $\mathrm{AL}=$ Assistant Lecturers. 


\subsection{Results and Discussion}

The rationale of the study was to examine the incremental effects of psychosocial factors and job satisfaction on academics' commitment at UCC. The independent variables were the five dimensions of psychosocial factors: the nature and scope of the work, work environment, promotion, co-worker relationship and work-family conflict, while the dependent variable was academics' commitment to the University. Job satisfaction was treated as moderator. Multiple close-ended items were used to collect data on these variables in order to test the hypothesis, as shown in Table 2 and Table 3.

Table 2. First model on the incremental effects of psychosocial factors and job satisfaction on academic staff commitment to the university.

\begin{tabular}{|c|c|c|c|c|c|c|c|}
\hline \multirow[b]{2}{*}{ Variables } & \multicolumn{2}{|c|}{$\begin{array}{l}\text { Unstandardised } \\
\text { Coefficients }\end{array}$} & \multirow{2}{*}{$\begin{array}{c}\begin{array}{c}\text { Standardised } \\
\text { Coefficients }\end{array} \\
\text { Beta }\end{array}$} & \multirow[t]{2}{*}{$\mathrm{t}$} & \multirow{2}{*}{ Sig. } & \multicolumn{2}{|c|}{$\begin{array}{l}\text { Collinearity } \\
\text { Statistics }\end{array}$} \\
\hline & $\mathrm{B}$ & Std. Error & & & & Tolerance & VIF \\
\hline $\begin{array}{c}\text { The nature and scope } \\
\text { of the work }\end{array}$ & 0.023 & 0.041 & 0.023 & 0.544 & 0.587 & 0.924 & 1.083 \\
\hline Work environment & 0.165 & 0.059 & $0.159^{\star *}$ & 2.804 & 0.005 & 0.465 & 2.152 \\
\hline Co-worker relationship & 0.008 & 0.035 & 0.009 & 0.217 & 0.828 & 0.867 & 1.154 \\
\hline Promotion & 0.152 & 0.062 & $0.124^{*}$ & 2.454 & 0.015 & 0.622 & 1.608 \\
\hline Work-family conflict & -0.309 & 0.061 & $-0.308^{\star *}$ & -5.087 & 0.000 & 0.406 & 2.462 \\
\hline Constant & 0.789 & & & & & & \\
\hline $\mathrm{R}$ & 0.663 & & & & & & \\
\hline R Square & 0.439 & & & & & & \\
\hline Adjusted R Square & 0.433 & & & & & & \\
\hline
\end{tabular}

Source: Field data $(2020){ }^{* *} p<0.01,{ }^{\star} p<0.05(\mathrm{~N}=261)$; Dependent Variable: Academics Commitment to the University.

Table 3. Second model on the incremental effects of psychosocial factors and job satisfaction on academic staff commitment to the university.

\begin{tabular}{|c|c|c|c|c|c|c|c|}
\hline \multirow[b]{2}{*}{ Variables } & \multicolumn{2}{|c|}{$\begin{array}{l}\text { Unstandardised } \\
\text { Coefficients }\end{array}$} & \multirow{2}{*}{$\begin{array}{c}\text { Standardised } \\
\text { Coefficients }\end{array}$} & \multirow[t]{2}{*}{$\mathrm{t}$} & \multirow[t]{2}{*}{ Sig. } & \multicolumn{2}{|c|}{$\begin{array}{l}\text { Collinearity } \\
\text { Statistics }\end{array}$} \\
\hline & $\mathrm{B}$ & Std. Error & & & & Tolerance & VIF \\
\hline $\begin{array}{c}\text { The nature and scope of } \\
\text { the work }\end{array}$ & 0.158 & 0.055 & $0.140^{* *}$ & 2.887 & 0.004 & 0.486 & 2.059 \\
\hline Work environment & 0.105 & 0.032 & $0.155^{\star *}$ & 3.287 & 0.001 & 0.716 & 1.397 \\
\hline Co-worker relationship & 0.139 & 0.061 & $0.126^{*}$ & 2.274 & 0.024 & 0.515 & 1.943 \\
\hline Promotion & 0.168 & 0.056 & $0.170^{\star *}$ & 2.984 & 0.003 & 0.352 & 2.839 \\
\hline Work-family conflict & -0.158 & 0.055 & $-0.140^{* *}$ & -2.887 & 0.004 & 0.486 & 2.059 \\
\hline Academics job satisfaction & 0.497 & 0.058 & $0.506^{* *}$ & 8.508 & 0.000 & 0.324 & 3.087 \\
\hline Constant & 0.553 & & & & & & \\
\hline $\mathrm{R}$ & 0.856 & & & & & & \\
\hline R Square & 0.672 & & & & & & \\
\hline Adjusted R Square & 0.665 & & & & & & \\
\hline
\end{tabular}

Source: Field data (2020). ${ }^{* *} p<0.01,{ }^{*} p<0.05(\mathrm{~N}=261)$; Dependent Variable: Academics Commitment to the University. 
H0: Psychosocial factors and job satisfaction have no statistically significant incremental effects on academic staff commitment at University of Cape Coast.

The multiple regression analysis involved testing of two models. In the first model, the dimensions of psychosocial factors were entered as independent variables. As depicted in Table 2, the variables that predicted academics commitment significantly in order of importance were work-family conflict $(\beta=-0.308$, $p<0.01)$, work environment $(\beta=0.159, p<0.01)$ and promotion $(\beta=0.124, p<$ $0.05)$. With the exception of work-family conflict, all the entered variables in the first model that were statistically significant contributed positively to academics' commitment to the University. However, the nature and scope of the work and co-worker relationship were not significant in the first model. It is however, significant, to observe that the total contribution of psychosocial factors to the variance in academics commitment to the University is 0.439 with an adjusted $\mathrm{R}^{2}$ of 0.433 . This means that psychosocial factors were able to explain $43.9 \%$ of the variance in academics commitment to the University.

Furthermore, the results may mean that improving the work environment such as refurbishment of some offices of academics and the enhancement of resources such as books, internet facilities, software, computers and others to the benefits of academics has helped in enhancing academics commitment. The findings are consistent with the comments of Milledzi et al. (2018) who posit that issues that affect the work environment and promotion of academics strongly predict their levels of commitment because these factors influence the desire and satisfaction of academics. In relation to work-family conflict, the results show that when it is not managed well can affect one's commitment significantly (30.8\%). This means, one's inability to plan and manage his/her time well regarding family and work roles and responsibilities will be ill-committed to the University.

In the second model, academics' job satisfaction considered as a moderator was entered into the model. The argument here is that when psychosocial factors are combined with academics job satisfaction, it will lead to incremental effects on academics commitment to the University. The results are presented in Table 3.

As indicated in Table 3, when job satisfaction of academics was considered, all the dimensions of psychosocial factors were significant predictors of academics commitment. Work-family conflict still contributed negatively to academics commitment. This shows that when psychosocial factors is combined with job satisfaction of academics, it help in boosting commitment levels of academics incrementally. That is, the explanatory powers of psychosocial factors are shared with job satisfaction to produce high level of academics commitment to the University. The total contribution $\left(\mathrm{R}^{2}\right)$ of the variables when job satisfaction of academics was introduced to the first model increased from 0.439 to 0.672 , while the adjusted $\mathrm{R}^{2}$ increased to 0.665 . The results further show that when job satisfaction of academics entered the first model, the rate of increase of the $\mathrm{R}^{2}$ was $34.7 \%$. Job satisfaction on its own, contributed $50.6 \%$ to commitment levels of academics. However, when job satisfaction is combined with psychosocial factors, academ- 
ics level of commitment to the University increases at a rate of $34.7 \%$.

The finding reinforces the argument that staff job satisfaction is a good mediator of their commitment. The study, therefore, rejects the hypothesis which states that psychosocial factors and job satisfaction have no statistically significant incremental effects on academic staff commitment at UCC since there is enough evidence to proof that the two variables have incremental effects on academics commitment level. The findings may mean that academic staff of UCC derives satisfaction from doing their work. They feel a sense of pride in doing this work. Although the work may be stressful for them as lecturers, because of proper time management they are still satisfied which influences their commitment to the institution. The findings are consistent with the comments of Saani et al. (2014) who posit that the nature and scope of the work accounted for $33 \%$ of the variance in teachers' commitment level. However, the findings regarding the nature and scope of the work is incongruent with the assertions of Milledzi et al. (2018) who assert that the nature and scope of the work is an intrinsic factor that influences job satisfaction of employees. Milledzi et al. added that academics in Ghana usually complain about their work and working conditions. This shows when academics perceived their work as stressful, it will results in low levels of commitment.

Again, the finding that academic staff of UCC perceived their work environment in positive terms seem to suggest that, they are satisfied with the resources at their disposal for teaching and research, satisfied with their office space, and also satisfied with the safety and security arrangement in the University. These factors contribute $15.5 \%$ to academics commitment to the University. The finding corroborates with the comments of Milledzi et al. (2018) who posit that most universities have provided academics with appropriate resources, office space and security to boost the conduciveness of their work environment. This situation has resulted in faculty members' satisfaction in the work environment which in turn has resulted to increase in their commitment to the University.

Again, it became evident that academics of the University are satisfied with the procedures for promotion in the University. Similarly, academics are satisfied with the requirements for promotion and their chance for promotion in the University. This may also mean that promotion criteria of the University are not cumbersome. The findings are incongruent with that of Noble and McCormic (2015) found that promotion procedures among primary school teachers are long, stressful and cumbersome.

Also, the finding that academic staff co-worker relationship positively influences their commitment means that they become more committed to the University when they begin to like people they work with, there is no bickering and fighting at work, and they feel safe when they are around their co-workers. The finding of this study confirms the comment of Staniok (2019) who asserts that employees in the public sector view their co-worker relationship positively, and perceived it to be a factor that helps in boosting their commitment. This means, university academics that have good working relations with their colleagues will 
report higher levels of commitment. This implies that university academics are social beings and therefore value their collegial interactions.

The results further show that work-family conflict was perceived negatively. This means, the time academics devote to their job does not keep them from participating reasonably in their household responsibilities. Also, the time they spend with their family often causes them to spend time on activities at work that are helpful to their career. This shows that the work schedules of academic staff of UCC do not conflict with their family lives. Balancing work and family responsibilities continues to be a significant cause of stress which has a negative effect on employee satisfaction and commitment (Kim, 2017; Staniok, 2019).

\subsection{Limitations}

Quite apart from the help the present study can give to practitioners and researchers in relation to the understanding of the concept, it has several limitations which include the generalisability, subject and situational characteristics. The sample of the study was limited to only permanent academics at UCC. The results may have restricted generalisability to academics in Ghana. Therefore, the results of the study can best be generalised to the study population only. In terms of the questionnaire, some may not be so apt in order to collect every needed data which would perhaps, add to the quality of information required for the study since all of them were close-ended in nature. Furthermore, because psychosocial factors, staff job satisfaction and commitment issues are time-based or evolve with time, some of the findings and conclusions of the study may be overtaken by time and the advent of new technologies.

\subsection{Conclusion}

Based on the findings of the study, it can be said that academics of UCC are happy with their work environment and promotion opportunities, as well as promotion criteria of the University. It can be said that academics of universities in Ghana attached so much importance to their work environment and promotion opportunities. Therefore, any policy that put them at a disadvantage with regard to these two factors will be met with sensitive reactions. Also, psychosocial factors and job satisfaction of academics are able to predict their commitment to the University incrementally. The conclusion therefore is that, irrespective of how well management of the University are able to enhance academic staff work environment, the nature and scope of the work, promotion, co-worker relationship and work-family conflict, if academics job satisfied with these psychosocial factors is not considered, it will translate into their low level of commitment. However, if these psychosocial factors are perceived positively, and academic staff job satisfaction is considered, it will translate into a significant increase in academic staff level of commitment to the University in the long run.

\subsection{Recommendations for Counselling and Educational Practice}

Based on the findings and conclusions drawn, the following recommendations 
are made:

The fact that academic staff perceives their psychosocial factors in positive terms calls for management support and encouragement. This is so because organisations that improve employees' work environment, the nature and scope of the work and promotion are more likely to enhance employee's job satisfaction and commitment. Nearly, all employees look for fulfilments in their performance such that, if a person becomes involved in performance that suits his workrelated options, he/she is likely to encounter satisfaction of job. This implies that, the University can put in place measures that will help enhance staff job satisfaction and commitment through guidance and counselling interventions. With effective counselling, staff psychosocial challenges can be reduced meaningfully, to help boost their commitment.

Based on the finding that the nature and scope of the work does not influence academic staff commitment when their job satisfaction is not considered, it is recommended that management of the University put measures in place to reduce the heavy work load on academic staff so that enough time can be used for research to generate new knowledge and ideas. For example, the responsibilities of departmental and faculty examinations, and other administrative responsibilities assigned to academic staff put additional responsibilities to them which in turn leads to a lot of stress on academic staff who are assigned with these responsibilities.

There is the need for the counselling unit at the study institution to liaise with management to provide information service and vocational counselling periodically to academic staff to help the staff internalize with the psychosocial factors of the institution. This can affect the job satisfaction and commitment levels of the staff; as a result, there is the need to provide information for the staff through vocational counselling.

\section{Conflicts of Interest}

The authors declare no conflicts of interest regarding the publication of this paper.

\section{References}

Abou-Hashish, E. A. (2017). Relationship between Ethical Work Climate and Nurses' Perception of Organisational Support, Commitment, Job Satisfaction and Turnover Intent. Nursing Ethics, 24, 151-166. https://doi.org/10.1177/0969733015594667

Alsemeri, H. A. (2016). Factors Affecting Job Satisfaction: An Empirical Study in the Public Sector of Saudi Arabia. Unpublished Doctoral Thesis, Melbourne: Victoria University.

Ansong, J. K. (2018). Job Satisfaction among Career Records Personnel in the Civil Service of Ghana. Unpublished Master's Thesis, Legon: University of Ghana.

Azeem, S. M., \& Akhtar, N. (2014). Job Satisfaction and Organisational Commitment among Public Sector Employees in Saudi Arabia. International Journal of Business and Social Science, 5, 127-133. https://doi.org/10.6007/IJARBSS/v5-i12/1943

Baah, A. R. A. (2015). Employee Satisfaction and Commitment as Antecedents to Service 
Quality in Hospital Service Delivery System. Unpublished Master's Thesis, Kumasi: Kwame Nkrumah University of Science and Technology (KNUST).

Cohen, L., Manion, L., \& Morrison, K. (2018). Research Methods in Education (8th ed.). New York: Routledge. https://doi.org/10.4324/9781315456539

Educational Management Information System EMIS (2019). Public Universities' Enrolment by Gender and Programme: Final Draft. Unpublished Report, Accra: GES/MoE.

Frempong, L. N., Agbenyo, W., \& Darko, P. A. (2018). The Impact of Job Satisfaction on Employees' Loyalty and Commitment: A Comparative Study among Some Selected Sectors in Ghana. European Journal of Business and Management, 10, 95-105.

Fuudia, B. (2017). Relationships between Job Satisfaction and Organisational Climate. International Journal of Applied Psychology, 107, 318-328.

Gothard, B., Mignot, P., Offer, M., \& Ruff, M. (2001). Careers Guidance in Context. New Delhi: SAGE Publications.

Ismail, N. (2016). Organisational Commitment and Job Satisfaction among Staff of Higher Learning Education Institutions in Kelantan. Unpublished Master's Thesis, Aman: Universiti Utara Malaysia (UUM).

Jain, S. (2019). Research Methodology in Arts, Science and Humanities. Oakville: Society Publishing.

Kim, B. P. (2017). Work Family Conflict and Its Job Consequences: From Attitudes to Behaviours to the Bottom-Line. Unpublished Doctoral Dissertation, Blacksburg, VA: Faculty of the Virginia Polytechnic Institute and State University.

Milledzi, E. Y., Boateng, W., Amponsah, M. O., \& Opare, J. A. (2018). Socio-Psychological Predictors of Job Satisfaction among Academic Staff of Universities in Ghana. The Online Journal of New Horizons in Education, 8, 149-159.

Nestor, P. I., \& Lary, P. (2016). The Relationship between Tenure and Non-Tenure Track Status of Extension Faculty and Job Satisfaction. Journal of Agricultural Extension, 54, 57-72.

Noble, J. J., \& McCormic, J. (2015). Organisational Commitment and Job Satisfaction in Primary Schools. Educational Management, Administration and Leadership, 43, 101-122.

Saani, A.-J. (2017). Constituencies' Participation in University Governance and Its Influence on Constituents' Commitment to the University. Unpublished Doctoral Thesis, Cape Coast: University of Cape Coast.

Saani, A.-J., Opare, J. A., \& Yarquah, J. A. (2014). The Complex Influence of School Organisational Culture on Teachers' Commitment to the Teaching Profession. Malaysian Journal of Education, 39, 101-107.

Sarstedt, M., \& Mooi, E. (2019). A Concise Guide to Market Research: The Process, Data, and Methods Using IBM SPSS Statistics (3rd ed.). Berlin: Springer-Verlag GmbH. https://doi.org/10.1007/978-3-662-56707-4

Ssesanga, K., \& Garrett, R. M. (2016). Job Satisfaction of University Academics: Comparative Analysis of Uganda and Kenya Academics. Journal of Higher Education, 61, 33-56. https://doi.org/10.1007/s10734-004-6346-0

Staniok, C. D. (2019). Work Commitment in Public Organisations. Unpublished Doctoral Dissertation, Denmark: Forlaget Politica, Aarhus University, Bartholins Allé.

Verret, L. B. (2012). Factors Affecting University STEM Faculty Job Satisfaction. Louisiana State University Digital Commons.

Yee, L. C. (2018). An Analysis on the Relationship between Job Satisfaction and Work Performance among Academic Staff in Malaysian Private Universities. Journal of Arts and Social Sciences, 1, 64-73. 
Yiğitol, B., \& Balaban, Ö. (2018). Relationship between Organisational Justice and Employee Satisfaction: Evaluation of Human Resources Functions (Electronic Version). http://lisbon2018.econworld.org/papers/Yiğitol Balaban Relationship.pdf 